\title{
Italian Manufacture Between Technological and Social Innovation
}

\author{
Elisabetta Cianfanelli ${ }^{1(\bowtie)}$, Eleonora Trivellin ${ }^{1}$, Marco Marseglia ${ }^{1}$, \\ Margherita Tufarelli ${ }^{1}$, and Gabriele Goretti ${ }^{2}$ \\ 1 University of Florence Design Campus, Via Sandro Pertini 93, \\ Calenzano, Fi, Italy \\ \{elisabetta. cianfanelli, eleonora. trivellin, \\ marco.marseglia, margherita.tufarelli\}@unifi.com \\ ${ }^{2}$ Nanjing School of Art and Design, Nanjing, China \\ gabriele.goretti.design@gmail.com
}

\begin{abstract}
The contribution has the aim of analyze the importance of traditional manufacturing systems in different contexts and how these are integrated adding value to the whole process. In the Italian and Tuscan context, in particular, it is useful to highlight how manufacturing production represents not only a production model but also an element of cohesion of the social environment.
\end{abstract}

Keywords: Artisan Know-How $\cdot$ Technology $\cdot$ Fashion $\cdot$ Interior $\cdot$ Design

\section{Introduction}

The contraposition of industrial-craft production models, if it ever existed in Italy, today seems to have lost most of the specific elements; the importance of tangible assets as fundamental for economic, sustainable and inclusive development has been reaffirmed. There has been a dynamic momentum in small and medium-sized companies: the possibility of access to digital tools has shown that the ability to innovate does not depend from the size of the companies, whereas, in the Tuscan reality, to which we refer, the most dynamic companies are those of small and medium size [1-3].

Therefore, the presence of large companies can not be considered the reason for attracting foreign capital to specific territories. Tuscany, according to the Financial Times, is the third most attractive region in Italy after Lombardy and Lazio, and the presence of small and medium-size enterprises is a witness to this.

However, the Italian context as overall should also be considered. This context is radically different compared to other European countries (in particular Germany, where the manufacturing sector is very strong), and compared to the realities of United States of America.

In Italy, manufacturing is often combined with crafts and we believe that this is the peculiar characteristic of the economy: on the one hand, the fragmentation has historically led to difficulties in interfacing companies with research institutions and public sector; on the other it has led companies to take root in the territory and become able to interpret its specificities, knowledge and values in general [4]. 
In this new context where the level of innovation is no longer proportional to company size, design plays an important role not only in materializing ideas but also in guiding and managing innovation.

The strengthening of the material product through digital technology has driven the reinforcement of the historical characteristics of the Italian products: attention to wellbeing and quality of life, as a typical capacity strengthened by a technological plus; intelligence of spaces and products (smart buildings, homes, objects); customization pushed up to the personalization, communication and storyelling able to increase the value of the product, but also to trigger virtuous behavior to rationalize consumption and favor circular economy processes. The appearance of new figures and new scenarios leads the designer to relate to production and to those who will use the final good.

\section{Experiences}

\subsection{Capsules of Digital Technology}

This research project started with a general analysis regarding the concept of craftsmanship and its relationship with the development of high-end Italian products, and how this relationship could be fostered by design culture. As primary result, this analysis can be synthesize in the existence of a " 21 st century craftsmanship" that is able to integrate various digital systems into its processes. As a part of this research, therefore, the work was conducted by introducing some technological solutions placed in specific stages of the manufacturing system, with the awareness and precise intention to not affect the artisanal processes and the historicized know-how of the company. On the contrary, the primary goal was, using the innovation abilities of digitali technologies, to create a flexible and innovative digital archive aimed at organizing the company "secrets", skills and products.

Hence, the research team has defined what kind of technological solutions suited properly to be introduced in the production processes inside those "capsules of digital technology".

The team worked together with clusters of craft businesses following two framework: the first one introduces the "capsules of technology" in the logistics and production processes within the supply chain; the other confines digital systems only in the compartments of communication. In the first case, the digital systems are inserted in the company processes according to a model of continuous implementation through numerical control machinery that support the latest craft processes. Digital tools often resulted useful for those laborious and repetitive processes, allow a new concept of "assistant" to the master craftsman to arise. This path towards innovation will come to enrich itself - in the very near future - with the inclusion of collaborative robots (co-bot) in the production processes of what becomes in all respects an advanced high-end manufacturing.

Differently, In the second framework, the result was an almost "viral" diffusion of the company values that establish a new type of communication and marketing dialects with the consumer and the distribution, from visual merchandising to interactive styling. 
Both frameworks represent two business development strategies aimed at different global markets and distinct customer areas that present significant examples of success and experimentation [5]. Companies that have already introduced digital systems in their processes have intervened in the first instance in those business sectors that generate the highest value in the final product, the areas of the "value chain" as communication, design, production, internal and external logistics, after-sales services and maintenance. The insertion of the "capsules of digital technologies" in these sectors took place through the use of digital platforms (IT infrastructures) intended for the creative and design areas of the company, capable of supporting the three-dimensional "digital archives" - previously created - of components and digital archives of knowledge that can be learned and transferred. The archives of knowledge, in particular, consist of an enrichment of the three-dimensional mathematical models that populate the company archive with embedded information related to the craftsmanship works to be carried out to achieve that result, and which tools to use.

We believe that this type of information placed in a shared digital environment such as the company archive can be considered one of the fundamental aspects for an Italian way of manufacturing 4.0. The reason for this, lies in the fact that the transfer of knowledge to new generations is encouraged within the processes of sharing. Likely, to promote the implementation of new technologies in the processes of high manufacturing with particular attention to detail, error corrections and quality improvement.

Thus, it is precisely in the "Training 4.0", based on the digital archives that took place in the sample manufacturing companies, oriented towards innovation, is one of the key aspects in the process of development of an Italian way of manufacturing 4.0, a very crucial aspect for the future of the Made in Italy production, which deserves to be investigated.

A company in which these "capsules of digital technologies" have been introduced, and with which the research group collaborates for the training of human resources to develop this area of advanced craftmanship [6], is Baldi Home Jewels. It is a company of furniture and furnishing accessories of high craftsmanship located in the Florentine territory and which exports all over the world. Baldi Home jewels represents an excellence both for the formal and material quality of the products and for the cultural value of the applied production processes that respond to the most ancient Florentine craftsmanship. The products are made by skilled craftsmen using hand-worked semiprecious crystals and stones, enriched by hand-carved bronze. Baldi's concepts take shape through innovative processes developed in the design department, making the creative process optimized through the use of a digital archive [7]. The archive determines the optimization of times and phases for the company, starting from the concept up to the development of the product and allows the structuring of a shared knowledge among all the sectors of the company [8,9]. The digital archive and its structure have become a strategic tool that permeates the entire process of supply chain and all the company areas. For a company in which the management of the "traditional" archive is often entrusted to people's memory, this aspect is extremely relevant; a digital database with the company departments has allowed to classify the products and their components, together with the definition of the joining systems, materials, finishes and treatments (Fig. 1). 

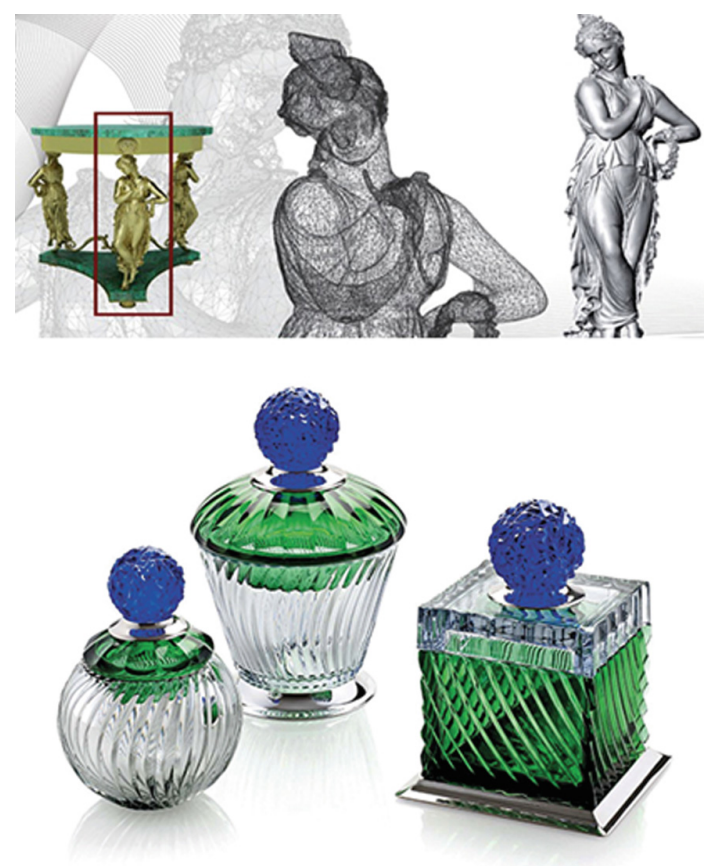

Fig. 1. Examples of product made with the digital archive support

The archive contains the entire development of the individual products and each component is characterized by an identification system (tag) and a code with the related technical description. The process allows the company to have an archive of craft knowledge starting from the creation of the work tools, up to the description of the correct use of those, indicating the areas of the product in which this tool is used. Today the departments of design, sales and communication, daily use the support provided by the digital archive through the creation of 3D catalogs, the use of augmented and virtual reality solutions; component archives and traceability of processes, from concept to warehouse, in all the internal and external phases of the company.

\subsection{Production Districts and Design Research}

Numerous projects carried out within the DIDA Architecture Department for Sustainability Design have as reference the Interior Technology and Design District to which we refer in particular in this text. The theme of the interiors in all its declinations - furniture, furnishing accessories, artistic crafts, campers and yachts - seems to be particularly strategic for the Tuscany region as the coexistence of those four sectors presents itself as unique at a national level. At the same time, in these sectors, more generally in the current scenarios, design seems to represent a discipline able to participate in the competition of the system in its whole. 
The intermediate actors of the Tuscany production system, which on our territories are represented by the technological districts, have the fundamental role of promoting technological transfer processes by meeting the demand for innovation and the offer that, in many cases, comes from research institutes and university.

For the small size of companies, of which we have illustrated the characteristics above, the relations with research institutes and university frequently happens through calls for funding. Nevertheless, another element of interest in these collaboration formulas is that they manage to bring together companies from non-homogeneous sectors, creating new synergies capable of strengthening the competitiveness of the territories.

In some ways, technological districts are the "antennas" in the territories and actions are carried out through the structures on different levels: «from Research \& Development projects for individual companies or business systems, to joint participation in European Union sharing projects tools to support innovation and technology transfer, until the definition of training plans that are strategic and support the growth of the sector at various levels.

The continuous relationship with the productive territory on the one hand, and with the research world on the other, allows the district to control systems and systematize the needs of the companies. Moreover it allows to filter, translate and spread the potential innovation of technologically advanced companies in a continuous matching activity multilevel and in different ways» [10].

In this scenario, the contribution of design discipline has led to the development of some furnishings for indoor spaces, transforming a traditional product into a productservice. The definition of the shape becomes essential to express the technological content and express the "sensitivity of the objects" and their ability to interact with the users. This is the case of the DOMO4MAB project, where some furnishings that are necessary for carrying out essential actions are enriched with integrated technologies, ICT, domotics and robotics, in order to support fragile users both in home care and in the cargiver family.

The project interprets the difficulties of companies operating in the social-health sector with the diffused idea that technological solutions are not able to be functionally integrated in objects with the aim of an improvement in autonomy, safety and comfort of the person.

Even in the furniture sector, the search team noticed that companies that integrate digital technologies in traditional furniture can actually improve the lives of users but with very high costs and difficulty in use.

Hence, the project has developed a bed, an integrated hob, an armchair and a door that express a strong attention to usability, moving away from the "hospital look" that this type of furniture usually have.

In some ways this work has focused on the following objectives:

1. an improvement in the service related to access by health or family workers;

2. an increase in security - with reduction in user injuries;

3. a reduction in costs for the public health and social service - with the same benefits with integrated home care services 
4. an increase in the quality of life, perceived above all by the users but also by the operators;

5. an increase in accessibility and sustainability of services by users.

The element of interest of these projects is in the new meaning given to consolidated objects by applying new technologies to a traditional field of manufacturing such as furniture. Moreover, not less important, considering that research organizations interact with companies of different sizes in an equal way, it is possible to state that small businesses are those that can increase the most their competitiveness from these operations.

Therefore, if on the one hand the role of design in this context is not only to give shape to products but also to relationships, on the other the goal of companies is to rethink their products according to new needs and new technologies. The relationships that are set up through this type of projects between companies that are different in structure and competence represent the capacity for innovation in Tuscany manufacture systems (Figs. 2, 3 and 4).

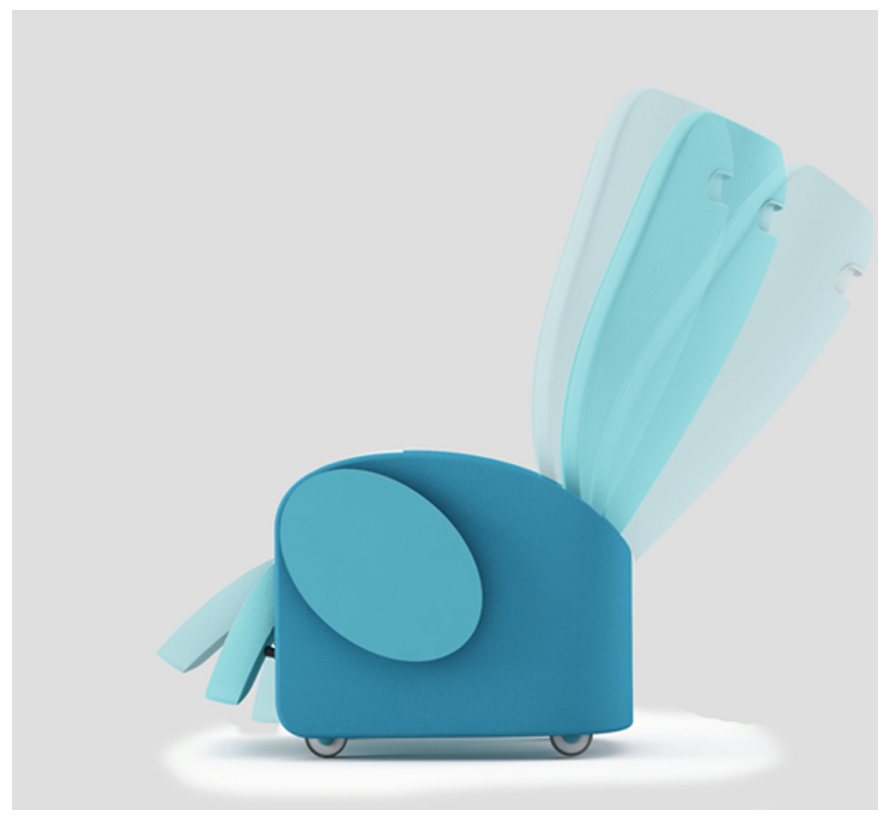

Fig. 2. Armchair of the DOMO4MAB system 


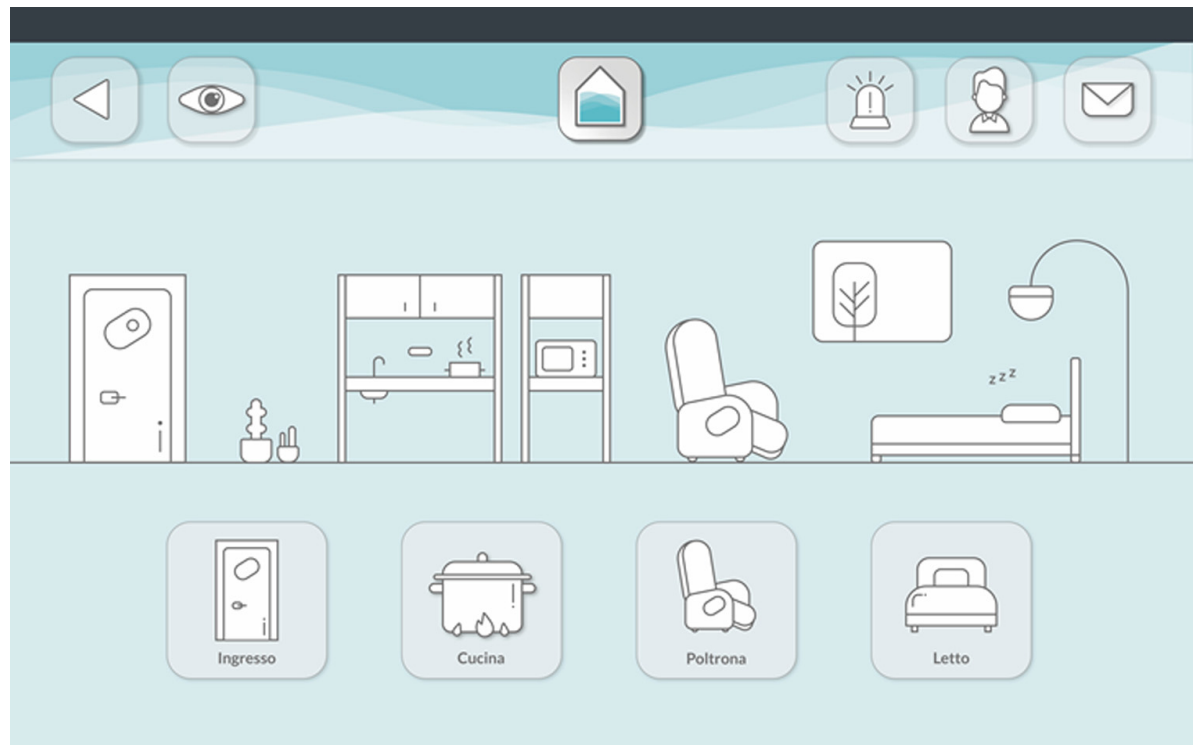

Fig. 3. Integrated kitchen DOMO4MAB

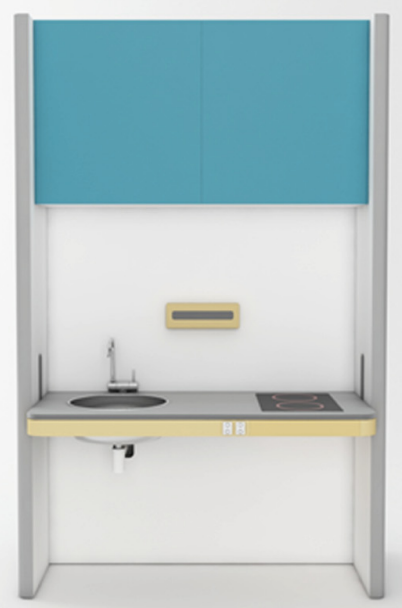

Fig. 4. The DOMO4MAB system interface 


\section{Between Digital and Social Innovation}

Traditional companies in Tuscany are able to be in different paths of innovation and, through the "guide" of design, they can interpret the changes.

Nonetheless, the contribution that the manufacturing enterprises can give is also in dealing with new realities that, with more or less strength, have become a consistent part of the productive landscape of many cities.

The context and the type of companies is constantly changing. As an example can be found in the Italian trade associations that in recent years have noticed that among the most dynamic artisans there are tattoo artists, for whom a particular framework has been developed, dealing with sanitary and artistic aspects.

The cities worldwide are full of laboratories for digital manufacturing that have among their characteristics those of having, within their own spaces, three-dimensional digital printing machines, numerical control cutters, laser cutter etc. We refer, of course, to the fab-labs (fabrication laboratories) generated on the first US model born at MIT.

These kind of labs have the know-how at its center, but little or nothing to do with traditional artisan laboratories. The former, present themselves as nodes of a global network with easy access, open and dynamic with no specialization required if not with the aim of allowing the knowledge and the use of digital manufacturing tools. The artisan laboratories, on the contrary, are often places difficult to access to learn of an exclusive knowledge, they are strongly linked to the identity of the territories and, at the same time, in many cases out of every institutionalized educational path.

Fab-labs are structures that move both on the level of training and research, offering logistical and financial assistance. In some peculiar cases is possible to find fab-labs overlap with the functions of the districts we discussed earlier. However, it should be considered that they are organisms that despite having relationships on the territory also with institutions, they have an autonomous structure and the ability to coordinate and bring together companies of different nature.

Districts, fab-labs and hubs (these two structures on our territories often develop in parallel, being bearers of similar principles) can get to integrate working with companies, enhancing the capacity for change as we will see in a project that we will describe below.

With the intention to compare the figures in fab labs with the traditional workshop artisans, we can find common elements like: the importance of "doing" as an experience; the fact that both have a critical relationship with mass production and consumption; common attention to customization.

We believe that tose common elements, more than the processing techniques, are the elements that, by synthesizing pre-industrial and post-industrial models, can perhaps configure a new model of development in the sign of sustainability declined in its various forms (social and cultural environment).

Where, as in Italy, traditional craftsmanship is declined in numerous ways, and continues to have an economic and cultural importance, it is difficult to find an equal dialogue with the new forms of "doing" like fab-labs. Perhaps it is too early to say whether they are two sides of the same coin or if they are completely independent phenomena expressing distant needs that only occasionally meet. 
In the fab lab makers express the importance of dialogue in an international community focusing on the use of digital technologies [11].

From a strategic point of view they have as objectives: to promote social innovation, especially by overcoming the three-tier scheme of public institutions, market, nonprofit, moving on fluid and predominantly non-hierarchical schemes; to reduce inequalities by facilitating access to technological tools in an easy way; to propose sustainable and inclusive community models that provide for responsible consumption and production. It is possible to recognize among these some of the objectives of the European 2030 Agenda, a tool that is able to hold together the interests of local communities with the big common aims.

\section{Innovator Networks}

We want to bring back some projects in which the University of Florence collaborates with this two realities, testifying that they can start a dialogue.

Among these experiences we can mention "Open Maker" a project that has obtained a European funding that "aims to facilitate the transition to a new production model, networking innovators, makers, manufacturing entrepreneurs, researchers and tech-

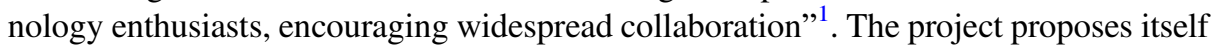
as an accelerator of the transition towards manufacturing 4.0 where, therefore, the nodes of material making acquires new values when combined with digital technologies.

The first activity of the project was to create a horizontal community that, in the name of collaboration, brought together makers, artisan business managers, designers, researchers, bloggers and ICT experts.

In this context we mention two projects: the first, represents the meeting of a glass manufacturing company and a fab lab. The company wanted to renew the production process with the use of digital technologies.

The fab lab, providing support for scanning, digital modeling and 3D printing of the company's artifacts, has simplified some manufacturing processes, has brought the customer closer to production, has made possible some otherwise unsustainable processing, especially from the economic point of view.

In many cases designer, or more in general the expert designer has had the role of verifying if the realization was coherent with the project idea presented and if there were some suggestions to be made.

\section{Conclusions}

A question that arieses as designers, is whether this shared and equal community, in order to address innovation in the best way, needs a governance that goes beyond the relationship between peers and that puts the importance of design back in the center. If the first step is a partnership of skills, in the long way this may be insufficient.

\footnotetext{
${ }^{1}$ [https://it.openmaker.eu/ consulted 20/1/2019].
} 
It is true that today the desire to act on the product or the final service is expressed not only by those who produce but also by those who use the product and therefore the traditional roles that defined the production processes appear increasingly blurred. Moreover, user satisfaction seems to pass also from its participation in the definition process which results in a rethinking of the meaning of the project [12].

The second project chosen as an example for this contribution, is still ongoing and called "OD \& M Open Design and Manufacturing",

As it is possible to read on the website, it is «a Knowledge Alliance dedicated to the creation of the best of openness, sharing and collaborating to create new value chains of innovation in design and manufacturing oriented to the social good. We are a community of students, university professors, researchers, makers, entrepreneurs and OD \& M practitioners distributed across Europe and China. We pursue multi-disciplinarity, horizontal collaboration, challenge-based working and collective discovery as the salient features of empowering learning environments leading to social innovation in design and production.

Universities, makers communities, enterprises and stakeholders, the OD \& $\mathrm{M}$ Alliance works to create meaningful flows of knowledge exchange, able to generate new research and concrete experimentation of products and processes based on the OD \& $\mathrm{M}$ paradigm». The project sees the participation of four European and two extra European nodes: Great Britain, Spain, Poland and China. On each of the European nodes there is a representation of fab-labs, traditional companies, high education institutes.

The primary activity for the program is to establish, for each European headquarters, a training course that also includes student mobility actions among the nodes. The aim of the Italian university course (LAMA Agency has collaborated representing the skills of hub-fab labs and CSMs representing traditional companies), is to create a figure able to relate different stakeholders into a process of economic and social development. In particular, the students will work with some traditional companies and with makers who will provide their technical-digital skills.

Students will learn the tools to make these two groups interact with each other and develop innovation projects enhancing the skills they have. All this with a view to understanding the scenarios of innovation and future development [13].

In conclusion, we recognize the importance of a leading figure who manages the processes of innovation; above all he/she should have the ability to dialogue and interpret "actors" and "scenarios" that appeared in distant worlds, developing communication codes sometimes very distant. This is an ambitious challenge that only in the future, perhaps not so far, we will be able to evaluate its validity.

\section{References}

1. Berta Giuseppe, Produzione intelligente un viaggio nelle nuove fabbriche, p. 168. Torino, Einaudi (2014)

2. Lombardi, M., Macchi, M.: I processi decisionali: ricerca e innovazione per l'esplorazione dell'ignoto, p. 232. Firenze, Nerbini (2016)

\footnotetext{
$\overline{2}$ https://odmplatform.eu consulted 20/1/2019.
} 
3. Magone, A., Mazali, T.: Industria 4.0. Uomini e mac- chine nella fabbrica digitale, p. 176. Milano, Guerini e associati (2016)

4. Lotti, G., Trivellin, E.: Una possibile strategia per il prodotto italiano. MD J. 4, 60-73 (2017)

5. Kotler, P.: Marketing 4.0: dal tradizionale al digitale. Hoepli editore (2017)

6. Goretti, G.: Maestri Avanzata Advanced Craftsmanship - percorso di ricerca nella manifattura moda Toscana. Aracne (2018)

7. Cianfanelli, E., Goretti, G., Tufarelli, M.: Reverse engineering and digital archives as a Resource for Practical Craft-Based Manufacturing Process. In: International Conference on Applied Human Factors and Ergonomics, pp. 280-289. Springer, Cham, (2018)

8. Campbell, D., Rey, C., Le Fort, M., Ehmann, S.: The Craft and the Makers Between Tradition and Attitude. Die Gestalten Verlag, Berlin (2014)

9. Zaccarelli, G.: La conoscenza condivisa. Franco Angeli (2016)

10. Bedeschi, I., Marseglia, M., Trivellin, E.: Cultura territoriale al centro: produzione, ricerca, formazione, MD J. 5, 70-81. ISSN 2531-9477 [online], ISBN 978-88-85885-00-4 (2018)

11. Santachiara, D.: Download Design, p. 144. Milano, 24 Ore Cultura (2017)

12. Manzini, E.: Design, When Everybody Designs: An Introduction to Design for Social Innovation, p. 256. MIT Press, Chicago (2015)

13. Verganti, R.: Design-driven innovation: cambiare le regole della competizione innovando radicalmente il significato dei prodotti e dei servizi, p. 282. Milano, ETAS (2009) 